\title{
A Lifetime of Relationships Mediated by Technology
}

By: Rebecca G. Adams and Michelle L. Stevenson

Adams, R.G., \& Stevenson, M. 2004. A Lifetime of Relationships Mediated by Technology. Pp. 368-393 in F. Lang \& K L. Fingerman, Growing Together: Personal Relationships across the Life Span. Cambridge.

Made available courtesy of Cambridge University Press: https://doi.org/10.1017/CBO9780511499852

This material has been published in Growing Together: Personal Relationships across the Life Span edited by Frieder R. Lang and Karen L. Fingerman. This version is free to view and download for personal use only. Not for re-distribution, re-sale or use in derivative works. (C) 2004 Cambridge University Press.

\begin{abstract}
:
Although recent technological developments have made transportation and communication faster, more efficient, and more accessible, relationship theorists and researchers have been slow to adapt. This chapter outlines a synthetic dynamic framework for the study of a lifetime of relationships mediated by technology, which integrates theories of individual development, life course, family development, and network change. Although this framework could be used to generate questions about the effects of any type of technology on social relationships, because communication via the Internet has become common and has already contributed dramatically to the reduction of geographic constraints on relationships, we illustrate the use of this framework by generating questions about its effects.
\end{abstract}

Keywords: technology | relationships | life stages | connection

\section{Chapter:}

Although recent technological developments have made transportation and communication faster, more efficient, and more accessible, relationship theorists and researchers have been slow to adapt. This chapter outlines a synthetic dynamic framework for the study of a lifetime of relationships mediated by technology, which integrates theories of individual development, life course, family development, and network change. Although this framework could be used to generate questions about the effects of any type of technology on social relationships, because communication via the Internet has become common and has already contributed dramatically to the reduction of geographic constraints on relationships, we illustrate the use of this framework by generating questions about its effects. ${ }^{1}$

Research has repeatedly verified Homans's (1950) proposition that increased interaction leads to increased liking (e.g., Hays, 1984, 1985). This suggests that any change in technology that

\footnotetext{
${ }^{1}$ The authors would like to thank Matthew Hembree and George Sanders for assistance in developing the
} bibliography for this chapter and Jenny Berggren for editorial comments. 
facilitates increased contact among family and friends would contribute to the solidarity of relationships. It is common knowledge that changes in communications and transportation technologies during the last 150 years have made contact among kin and friends, whether separated by small or great distances, less expensive, faster, and easier. Although numerous studies have been conducted on the social impact of previous technological developments, such as the telephone and automobile (e.g., Fischer \& Carroll, 1988; Martin, 1991; Pool, 1983), the effects of the most recent developments in electronic communications on social relationships have not been studied extensively (see Parks \& Floyd, 1996, and Watt \& White, 1999, for exceptions). Furthermore, researchers who have studied the effects of technology on social relationships have not examined how these effects might vary by stage of individual or life course development. As a first step toward addressing these deficits in the relationship literature, we provide a theoretical framework to guide future research on how communications and transportation technology might facilitate or inhibit the evolution of family and friend relationships at various stages of individual or life course development. Although this framework could be used to generate questions about the effects of any type of communications or transportation technology on relationships, because communication via the Internet is "becoming normalized as it is incorporated into the routine practices of everyday life" (Wellman, Haase, Witte, \& Hampton, 2001), has already contributed dramatically to the reduction of geographic constraints on social relationships, and will continue to have a tremendous impact on social relationships in the future, we focus here on the generation of questions regarding its effects.

Although the main purpose of this chapter is to suggest directions for future research, it is useful first to examine the extent and variety of changes in transportation and communications technology and the state of the literature on Internet technology as a mediator in social relationships. Examining the changes in technology serves as a reminder of how dramatically the context for social relationships has changed as geographic constraints on social interaction have been reduced. Surveying the literature on technology as a relationship mediator serves to demonstrate how slowly researchers have changed their perspectives to adapt to recent changes and how little attention they have given to the potential interaction effect among age of relationship participants, use of technology to communicate, and the character of social relationships.

After summarizing recent changes in communications and transportation technology and reviewing the literature on Internet communications as a social relationship mediator, we present our framework, which integrates four dynamic social theories, and discuss the implications of each of the four theories for understanding the impact of Internet technology on relationships. The dynamic perspectives we examine include structural theories of the life course and network change and process theories of individual and family development. In conclusion, we suggest directions for future research on a lifetime of relationships mediated by technology.

\section{Changes in the Technological Context ${ }^{2}$}

In this chapter, we focus on one type of communications technology, namely the Internet, as a mediator of social relationships. In order to understand the changing context of social relationships, however, it is important to examine the history of transportation technology in

\footnotetext{
${ }^{2}$ The information in this section was previously reported in Adams (1998).
} 
addition to the history of communications technology, because a mere two hundred years ago, communication across distances was dependent on transportation. Messages could only be sent via animals or people who were traveling. Letters were sent when someone happened to be going in a certain direction or, later, by the Pony Express ("Pony Express," Encyclopedia Britannica, 1997; "Postal System," Encyclopedia Britannica, 1997).

When the telegraph was developed in 1844, communication was no longer dependent on transportation. For the first time, messages could be sent without someone traveling, and they could be sent faster than someone could carry them (Carey, 1983). By 1861, the Pony Express had ceased operation and the transcontinental telegraph system had been fully established (Klein, 1993; "Pony Express," 1997). On December 12, 1901, forty years after the first transatlantic telegraph cable had been laid, Marconi sent a message by wireless telegraph across the Atlantic. Although the wireless was used mainly to send commercial messages, amateur enthusiasts, forebears of the current Internet junkies, began communicating socially with one another (Warthman, 1974; Reynolds, 1977-79).

During the twentieth century, both communications and transportation have become faster, more efficient, and more accessible. Although Bell invented the first telephone transmitter in 1876, the diffusion of the telephone started out slowly (Warthman, 1974). By 1900, only two out of every one hundred Americans had telephones, and even most of these were instruments of convenience and commerce rather than tools for friends to use in keeping in touch (Fischer \& Carroll, 1988). By 1915, transcontinental telephone service was possible (Warthman, 1974). According to Fischer and Carroll (1988), on the eve of the Great Depression, 41\% of all homes in the United States were equipped with a telephone, and it had become firmly established as a social instrument, at least among the middle class. Full saturation did not occur until the 1960s.

Transportation technology developed rapidly over this same period. In the early nineteenth century, commercial steamships began operation in the United States and Great Britain and shortly thereafter steam locomotives were available as transportation ("History of Technology," Encyclopedia Britannica, 1997). Then came automobiles and airplanes. In 1895, there were 3,700 car owners in the United States; by 1900, there were 8,000. In 1903, both the first flight by the Wright brothers and the first continental crossing by automobile occurred (Hokanson, 1988). The Lincoln Highway opened in 1915, making it possible for people to cross the United States by car relatively easily (Hokanson, 1988). In 1918, the first airline was formed in Germany. By the 1930s, three airlines were developing worldwide fight patterns, and one-fifth of all Americans owned automobiles ("Formation of airlines," Encyclopedia Britannica, 1997; Fischer \& Carroll, 1988). By the 1960s, most people owned cars and air transportation was easily available to passengers who could afford it.

By the 1970s, it was relatively easy for people with adequate financial resources to talk and visit with people who lived all over the globe. The development of the Internet facilitated almost instant and easier communication with large numbers of people worldwide. According to Castells (1996), there were only twenty-five computers on the Internet in 1973. As late as the 1980s, there were only a few thousand Internet users. By 1997, 37.4 million American households had computers, and 56.7 million Americans aged three years and above used the Internet (U.S. Census Bureau, 1997). Experts predict that one day the Internet could connect 600 
million computer networks (Castells, 1996). Although most electronic communication is currently mainly text-based, multimedia applications for on-line communication are being developed (Paccagnella, 1997). We are now hearing about the possibilities of virtually projecting people to another location, once again blurring the distinction between transportation and communications (Rheingold, 1991). This time, however, rather than communication being dependent on transportation, transportation-like experiences will be dependent on communications technology.

\section{Technology as a Mediator of Social Relationships}

Despite the constant changes in the technological context of social relationships, most of the theory that researchers use to guide their endeavors is based on the assumption that kin and friend relationships are formed and maintained primarily, if not exclusively, through face-to-face interaction (Adams, 1998). For example, psychologists who study interpersonal attraction have focused on the importance of visual cues, including how physical appearance plays a role in attraction, what gestures, facial expressions, and tie-signs people use to indicate involvement, and how spatial placement varies by closeness of relationships (see Short, Williams, \& Christie, 1976). Similarly, sociologists are still influenced by classic conceptions of the groups (or "primary groups") through which the individual becomes integrated into society as involving repeated, intimate, face-to-face contact (Cooley, 1983 [1909]). In the context of these intellectual traditions, scholars focus their research on understanding face-to-face relationships to the exclusion of relationships that exist across distances.

As Adams (1998) has argued elsewhere, the focus on physically copresent relationships made some sense in the technological context in which these territorially bound theories developed. After all, it was not possible until recently to travel or communicate with people who lived at a distance with enough frequency to form a relationship with them. Even maintaining already established relationships across distances was problematic until recently, due to the expense and amount of time required to travel or communicate. On the other hand, at least since industrialization and urbanization took root at the turn of the nineteenth and twentieth centuries, some people have maintained relationships with friends they had previously met in face-to-face encounters, and it has been fairly common for families to be dispersed around the globe.

Nonetheless, even as recently as the fifties and sixties, both quantitative and qualitative researchers focused their attention almost exclusively on local relationships. Survey researchers demonstrated their blindness to the importance of long-distance relationships by relying mainly on global questions regarding the frequency of face-to-face interaction with friends and family members to measure social integration (e.g., Blau, 1961; Pihlblad \& McNamara, 1965; Rose, 1965). Most of the questions they posed about relationships were designed to measure face-toface contact specifically and thus asked about how frequently the respondents "saw" or "visited" their family and friends (see Adams, 1989, for a discussion of measurement issues in relationship research). Even when they did not use wording that assumed face-to-face contact, the issue remained "frequency of contact," not "quality of interactions," and they made no attempt to study long-distance and face-to-face relationships separately. 
Perhaps more understandable given their focus on studies of various "settings," during this same period of intellectual history, ethnographers also focused on physically proximate relationships to the exclusion of long-distance ones. It is probable that the relatively poor inhabitants of Tally's Corner (Liebow, 1967) did not have any ties outside of their neighborhood, but it is more difficult to believe that the Organization Man (Whyte, 1956) and his family and the Levittowners (Gans, 1967), all now famous middleclass transients, did not. Even the working-class inhabitants of Street Corner Society (Whyte, 1943) and the Urban Villagers (Gans, 1962) probably maintained ties with their relatives who still lived in Italy, but these relationships are not discussed in these volumes. Although these ethnographers did not chronicle everyday life in these mid-century communities in the idealistic way it is now often depicted in the media, their descriptions do remind us of the fictitious community portrayed in the film Pleasantville (Soderbergh \& Ross, 1998). Pleasantville was an island of civilization with nothing beyond its borders. In these ethnographies, the term "the outside world" was used to mean the worlds of work, education, and health care. Participation in these worlds did not necessarily take the inhabitants outside of the geographic boundaries of the neighborhood (Gans, 1962). The implications of close connections with significant others beyond these neighborhood boundaries were not considered. It was as if the outside world, and the friends and relatives who inhabited it, did not exist.

In the late 1960s, however, researchers began to question the territorially bound assumptions that formed the foundation for earlier research. For example, Litwak and Szelenyi (1969) challenged Parsons's (1949) argument that the nuclear family is the most adaptive form in contemporary society because geographic mobility was common and long-distance connections were difficult to maintain. They posited that changes in technology had led to new forms of primary groups and that "contacts among extended kin can be maintained despite breaks in face-to-face contact; neighborhoods can exist despite rapid membership turnover; and friendships can continue despite both of these problems" (Litwak \& Szelenyi, 1969, p. 465). At the same time, survey researchers began to ask questions about letter writing and telephone calls or at least eliminated the wording from their questions that implied that they were only interested in face-to-face contact. A decade later, including such questions on survey instruments was common, and theorists began arguing that "intimacy at a distance" was the type of relationship people preferred with their family members (Rosenmayr, 1977).

Similarly, as communications and transportation technology developed, theorists began addressing the topic of communities based on beliefs and interests rather than on shared territory (Webber, 1973; Effrat, 1974). Once these scholars recognized that "despatialized communities can cross city - and national - boundaries" (Craven \& Wellman, 1974, p. 78), the theoretical climate made it sensible for researchers to focus on long-distance relationships in addition to the physically proximate ones that had always demanded their attention. Survey researchers began asking "how far away" friends and family members lived, recognized the existence of commuter marriages and long-distance romantic relationships, stopped eliminating nonlocal friends and family from consideration, and started conducting separate analyses on information about local and nonlocal relationships.

It has been over two decades since theorists gave researchers permission to study long-distance relationships, but very little work in this area has been published. Exceptions include Rohlfing's 
(1995) study of long-distance friendships and Cuba's (1991, 1992; Cuba \& Hummon, 1993) research program on the effect of geographic location on older families. This relative lack of studies on long-distance relationships is unfortunate, because now that the Internet and other forms of electronic communication are common and begging to be studied, relationship researchers are left only with the territorially bound theories of a much earlier intellectual age to guide them.

Although researchers have now been studying on-line interactions for some time (e.g., Smith \& Kolluck, 1999), they have not paid much attention to the effect of technology on personal relationships. Perhaps this is because the theoretical perspectives that inspired the early research on this topic suggested that relationships would be unlikely to develop in an electronic context. For example, in an early publication on this topic, social presence theorists argued that on-line communications are not perceived to be as intimate as face-to-face exchanges because they are asynchronous and text-based (Short et al., 1976). Similarly, others argued that due to the reduced number of social cues available for participants to use and interpret, electronic communication is seen as less personal and more negative (Siegal, Dubrovsky, Kiesler, \&McGuire, 1986). The online context is evolving, however, and now not all communication is asynchronous or text-based and an increasing number of social cues are available. Furthermore, although not many researchers have studied on-line relationships, enough of them have for it to be clear that relationships do develop on-line (e.g., Parks \& Floyd, 1996).

Few scholars have studied relationships that develop on-line. Of these scholars an even smaller number have paid attention to the effect that the use of electronic means of communication has on relationships that originally develop in face-to-face contexts and morph into long-distance relationships, or to the effect it has on relationships between people who still live near each other (see Wellman, Haase, Witte, \&Hampton, 2001, for an exception). E-mail, instant messaging, and chat rooms all provide people with opportunities to keep in touch with their family and friends between face-to-face encounters, no matter how frequently those face-to-face encounters take place or how little distance people have to travel to have them. Electronic communication can mediate all types of relationships.

\section{Research Findings on the Effects of Internet Technology in Social Relationships}

While the focus of this chapter is on Internet technology and relationships over the life span, current studies do not extend to all stages of development. Most studies focus on adults, although a small amount of work has been done involving children. The group almost entirely absent from this literature is that of old age.

Although researchers primarily have focused on relationships involving adult Internet users, a University of California-Los Angeles research study (2001) shows that all ages report using this form of communication technology. Of the sample of 2,002 participants, $72 \%$ reported Internet use in 2001, an increase from $67 \%$ in the year 2000. Fifteen percent of Internet users were children ages 18 years and younger, 69\% were ages 19 to 55 years, while only $16 \%$ were older adults ages 56 years and older. Perhaps the research focus on adults merely results because they are a more viable pool of participants. 
The following review of the literature is organized by stage of the life course - childhood, adulthood, and old age - and within adulthood into the major topics found in both academic journals and the popular press, including the major foci of activities (education, work, and leisure activities) and types of relationships and processes (mate selection, dating, friendship, and social isolation). Although the popular press, such as newspapers and magazines, would typically not be included in an academic literature review, our search for information on this topic had to be expanded beyond peer-reviewed journals because little research exists in this area. As a result, few of the articles that are reviewed here are theoretically driven or methodologically sound. We can say, with confidence, that there is considerable room for future research on the mediating effect of technology on relationships.

\section{Childhood}

Most children are familiar with computers. In 1997, about three out of four children had access to computers (U.S. Census Bureau, 1997). The most abundant information regarding children concerns parental fears about the on-line experiences their children might have and the resulting need to monitor their computer use. For example, journalists suggest the importance of regulating children's access to information and of monitoring the information to which they are exposed (Carlin \& Surk, 2000; Gibson, 2001). One author (Gibson, 2001) discussed the privacy policies of children-targeted sites. While parents might assume that historically child-friendly agencies and companies will remain so in virtual space, Gibson shows that this is not always the case. Many sites require children to $\log$ in in order to gain access to their sites. How safe is it for children to provide personal information in order to play a game or gain information about a treasured character? On the other hand, to what kinds of information do these sites expose children? The point made here is that children's behavior on the Internet should be monitored in order to preserve their safety and age-appropriate education.

Iliff (2002), a high school student herself, designed a study of middle school students to challenge these conclusions. In her study of all students who had Internet access who attend one middle school in a southeastern city, she found that students were exposed to some of the dangers that concern parents and the media - personal questions posed by strangers, pornography, cons, and foul language, but that most of the students handled these problems effectively, eliminating any threat to their safety or well-being. She argues that many of the restrictions parents impose on their children's on-line activity are unnecessary for this reason and, furthermore, that these restrictions undermine the parent-child relationship. The atmosphere of distrust thus created can interfere with the children's social life, which is increasingly supplemented by on-line interactions with school friends.

\section{Adulthood: Foci of Activities}

The Internet is not only used for social activities, it is also used to acquire an education, accomplish work-related activities, and pursue leisure interests. In this section, we summarize some of the research on on-line activities in these areas and discuss its implications for social relationships. 
Education. Examinations of technological influences on education suggest that faculty contact with students is enhanced. For example, in their focus-group study of active on-line teachers, web enhancers, and faculty interested in teaching on-line, Adams and Ammons (2000) found that faculty who taught on-line felt that they interacted more with students than they did when they were teaching traditional face-to-face classes. They warned faculty who were thinking about teaching on-line that "you really have to enjoy interacting with students" to be a successful online instructor. Tiene (2000) investigated the advantages and disadvantages of on-line discussion groups, or class listservs, in graduate courses, and found that students enjoyed the asynchronous aspect of the written form of discussion. Mild frustrations arose, however, with technical barriers (limited access when network was down, losing a post) and the lack of visual cues (possible misinterpretation of statements). The authors concluded that the on-line discussion forums were a good supplement to, but should not replace, in-class discussions. An article published in the Chronicle of Higher Education (O'Donnell, 1998) described a college professor's positive experience with e-mail communication with students. He suggests that contact may overcome difficulties posed by illness, studies or visits abroad, social apprehensions, and time.

Work and Work Environments. Research on the interplay between work and the Internet primarily focuses on physically absent employees and outcomes such as feelings of social isolation. The creation of "virtual offices" portrays an image of an employee, primarily female, working from her home office and enjoying the advantages created by being physically absent from the workplace (Duxbury, Higgins, \& Thomas, 1996). Some of these advantages include flexibility in time (i.e., setting one's own hours, breaking up the workday into several segments) and physical location (i.e., working from a remote setting, geographic mobility, ability to work from vacation locale) (Duxbury et al., 1996). The primary disadvantage that employees of virtual work environments report is social isolation (Duxbury et al., 1996; Tolson, 2000). However, it is unclear whether social isolation is actually an outcome of a virtual work environment. For example, are people who prefer little social interaction simply drawn to jobs that enable remote communication? Also, how different are the growing number of cubicle-style offices from virtual work environments? Researchers need to be sensitive to these questions while developing research methods to investigate this area.

Leisure. While many people suggest that technology is a form of leisure, few social scientists or media journalists have discussed the outcomes of technology on leisure behavior. In fact, our review found only one article with this specific focus and it was written as an investigation of possible outcomes with hopes of providing the catalyst for more research in this area (Bryce, 2001). Bryce points out that the Internet blurs domestic, virtual, and commercial leisure by redefining our concept of space. We use the Internet for a variety of tasks, such as communicating, disseminating and gathering information, socializing, shopping, and entertaining (games). Instead of the traditional means of completing these leisure tasks that require one to be in a specific physical space, the Internet has provided the opportunity for virtual spaces. The Internet, one type of virtual space, allows individuals to partake in various types of leisure activities without changing physical space.

It is important to note that cyberspace enables deviant leisure activities as well as nondeviant ones (Bryce, 2001). That is, the possible anonymity and solitary nature of Internet use provides a safer environment than non-Internet leisure for activities such as pornographic viewing, criminal 
activity (e.g., pedophilia, obtaining information illegally, on-line stalking), and sexual experimentation. The ability to act freely on deviant desires (e.g., to access pornography) may influence social and intimate relationships by decreasing satisfaction with intimate partners (Zillmann \& Jennings, 1988). Further information is not known about the effect of open access to deviant leisure activities on relationships.

\section{Adulthood: Types of Relationships and Processes}

Theoretically, any type of relationship can develop or be maintained through on-line interaction. The popular media has focused most of its attention on mate selection and dating and on sexual relationships, but the limited research by scholars examines on-line friendships and the potential of the Internet to provide computer users an excuse to avoid face-to-face interaction and therefore isolate them from others.

Mate Selection and Dating. The literature regarding mate selection and dating (i.e., beginning relationships) via computer technologies is sparse when articles on sexual relationships are excluded. A content analysis of one hundred personal ads on the Internet placed by college students suggests that security is an important issue to these young adults (Milewski, Hatala, \& Baack, 1999). That is, on-line personal ads contained little personal information when compared to newspaper ads. However, some of the advantages of on-line personals over newspaper ads include: 1) ease of locating people with similar interests; 2) use of search engines to create selective search criteria for possible dates; 3 ) fast and low-cost nature of the Internet; 4) possible anonymity; and 5) portrayal of one's own or socially expected ideal.

Some people may benefit more than others by using the Internet to locate a possible date. For example, people with relationship inhibitions, such as shyness or low self-esteem associated with appearance, use the Internet to find an appropriate match more often than those who are less shy or have higher self-esteem (Scharlott \& Christ, 1995). In addition, those persons interested in locating a dating partner, particularly women, may feel more secure by the anonymity the on-line search offers. Additional research must be conducted, however, to confirm and expand these findings. Scharlott and Christ (1995) used a convenience sample with a problematic methodology, thereby restricting the type of conclusions that may be drawn from their efforts.

A popular press article may assist these women by providing advice for moving the on-line relationship to one that is off-line (Goldsborough, 1998). In general, Goldsborough suggests that women use common sense, understand the risks, and recognize that negative experiences, however rare, may occur. This advice is likely to enable women to feel more confident and comfortable in their on-line search for partners.

Sexual Relationships. A high proportion of the traffic on the Internet is sexual in nature (Mills, 1998; Waskul et al., 2000). Waskul and colleagues (2000) used participant observation and qualitative interviews through sexually oriented on-line chat rooms and discussion forums to investigate the use of the Internet in sexual relationships. Specifically, these authors were interested in the "disembodiment of self," or the virtual portrayal of the human body and human interactions. The Internet was found to provide a mechanism for the "experience of multiplicity" (p. 394), or the ability to portray numerous selves that are situationally defined. Waskul and 
colleagues (2000) suggest that these on-line portrayals of selves are unique because of the disembodiment of self, or the absence of a physical body that usually restricts the fluidity between the self and portrayals of the self to others. As such, participants have the ability to become their ideal self, which may or may not be consistent with their physical characteristics. In addition, these multiple selves facilitate involvement in situations not otherwise experienced, such as various experimental sexual relationships. Waskul and colleagues (2000) suggest that newer communication technologies, such as Internet chat rooms, challenge traditional assumptions about the interplay between body, self, and the social environment. The body can no longer be thought of as a starting point or anchor for our self, but is open to redefinition. Once defined as the most stable characteristic, our sense of who we are and where we are in physical space is now malleable due to virtual space. These unreliable characteristics of our selves invariably influence interactions with others and subsequent reactions to these relationships.

Rather than merely limiting his study to sexual encounters on-line, Mills (1998) provided support for the suggestion that Internet sexual relationships influence relationships off-line through his research using participant observation and ten on-line interviews of "randomly chosen people in a number of different chat rooms" (p. 43). Instead of focusing on the self, however, Mills approached the use of sexually oriented Internet conversation as a threat to off-line intimate relationships. While the absence of physical contact may suggest that the cyber encounters are innocent, infidelity has occurred in the mind of the participant. Mills (1998) argues that more traditional types of threats to intimate relationships have had time for responses to develop to prevent encounters from expanding into an affair. Internet-based communication, however, is a novel temptation that may pique curiosity and progress into intimate exchanges before a conscious decision is made. This process may evolve from the lack of identified cues and previous experience with "virtual" relationships. Research may assist in this area by identifying and describing the early stages of interactions between people in virtual communication settings and distinguish between relationships that progress into intimate exchanges from those that do not.

Friendships. Although very few researchers are focusing attention on online friendships, the research in this area tends to be of higher quality than the research in some of the other areas we have discussed. On-line friendships are found to be common among Internet users belonging to a variety of Internet newsgroups (Parks \& Floyd, 1996). The progression of these friendships has been found to follow similar paths of development as off-line relationships (Parks \& Floyd, 1996). The relationships that form are typically transformed into off-line relationships, indicating that Internet newsgroups serve as another context for personal relationship formation.

On-line friendships are not a substitute for off-line relationships, but may precede them in some instances. In fact, the Internet may facilitate the identification of appropriate friends for individuals who want to meet someone with specific characteristics, qualities, or interests. For example, someone may join a newsgroup related to a specific hobby or political concern to meet people who share this concern or knowledge (Parks \& Roberts, 1998). In their study of visitors to the National Geographic Society web site, however, Wellman, Haase, Witte, and Hampton (2001) found that people's on-line interaction supplements their face-to-face and telephone interaction without increasing or decreasing it. 
Social Isolation. Next to sexual relationships, the literature on social isolation and current technologies contains the largest number of articles. Overall, there is a debate over whether or not computers, especially the Internet, lead to socially isolated individuals or provide a vehicle for interaction. A lack of consistency in findings likely stems from an absence of appropriate research methods. Using convenience samples, disregarding important mediating factors, and using poor measurements result in findings that should be considered as the basis for future research rather than as a basis for practice or policy. Unfortunately, the popular media publishes research findings without weighing the potential importance of these methodological deficiencies.

A controversial longitudinal study published in American Psychologist (Kraut, Patterson, Lundmark, Kiesler, Mukopadhyay, \& Scherlis, 1998) followed new Internet users and their household companions over a one to two year time period. They found that frequent Internet use was associated with less communication with household members, declines in the size of social networks, and increased depression and loneliness. Several responses challenged the findings of Kraut and his colleagues. First, it was noted that these researchers did not take into account the expected increase or decrease of social network size given one's position in the life course (Shapiro, 1999). Second, Kraut et al. (1998) selected their sample from citizens who were highly involved in their community. Shapiro (1999) explained "whenever a sample is selected on the basis of high values of some variable, there is a tendency for that variable to decline (regress) toward more average values (the mean) over time." Third, the effect sizes Kraut and colleagues (1998) found for outcomes of distress were minimal (Rierdan, 1999). In addition, the infrequent use of the Internet (average of less than three hours per week) led Rierdan (1999) to discount Kraut and associates' suggestions for political and personal implications. The fact that the article received front-page attention from the New York Times (Harmon, 1998) suggests the importance of carefully conducted research.

In the investigation of the relationship between computer-mediated communication and social isolation, it may be important to ask whether the Internet will replace face-to-face

communication. Research conducted by Flaherty and colleagues (1998) suggests that on-line communication is not a functional alternative to face-to-face communication. Likewise, a review by Galston (2000) suggests that on-line groups fulfill certain emotional and psychological needs, but do not meet all needs of individuals or society. For example, several articles suggest that information technology such as the Internet influences lifestyles by making it possible to shop from home, to cut back hours at the office to work from home (O'Toole, 2000), and to spend less time in recreation, social interaction, and social gatherings (Perry, 2000). Nonetheless, the Internet allows communication between family members who are geographically distant and searching capabilities for friends and family whose contact information has been lost. Galston (2000) points out that while computers facilitate contact over distances, one cannot share a cup of coffee, give a hug, or offer touches of understanding. Such restrictions may, depending on the conceptual definition used, be classified as social isolation.

\section{Old Age}

Census data shows that $21 \%$ of adults aged 55 and older have a computer in their household, yet little is known about their use of computers and how it affects their relationships and daily lives 
(U.S. Census, 1997). Although we found no published studies of the use of the Internet by older adults, Jennings's (2001) observations, written as part of the requirements for a graduate student internship, are thought-provoking. Her internship involved helping older adults who lived in a multilevel care residential community use their computers. She found that the majority of the residents did not own computers but those who did showed a great deal of interest. Interest and use was not correlated with age, suggesting that previous exposure to computers did not affect their attitudes. On the other hand, their physical and mental health did affect residents' use of computers. Residents who were physically healthier were more interested in using a computer and had better control of the devices needed to access information, such as a keyboard and a mouse. Residents who were mentally healthier and had no memory problems were more interested in using the computer because they had an easier time understanding and remembering instructions. These findings suggest that without the development of more age-appropriate equipment, the frail elderly will be unlikely to use the computer to maintain relationships.

\section{Conclusions}

Research on relationships and Internet technology is in its infancy. Consequently, current information is generally not theoretically grounded nor has it been rigorously tested. Computer use is on the rise in the United States and is expected to continue to increase (U.S. Census Bureau, 1997). What we know thus far suggests that computer technology may affect various aspects of relationships, increasing interactions in some cases while decreasing them in other contexts. Some relationships may be nurtured using information technology, while others may suffer neglect. Furthermore, computers have an age-related yet complex impact on the formation, process, and structure of relationships.

\section{Synthetic Dynamic Framework for the Study of a Lifetime of Relationships Mediated by Technology}

Although we have organized the review of the literature on on-line relationships roughly by stage of the life course, the literature in each category is too sparse and the topics vary too much across age categories to enable us to make generalizations about how the use of the Internet to establish and maintain relationships varies by age. Furthermore, none of these studies, whether they were scholarly or popular, specifically examined the effects of age on any computer use or relationship outcome variables. Perhaps the neglect of this topic by researchers can be explained by the lack of a theoretical framework to guide their endeavors. In the face of the absence of empirical data from which to derive grounded theory, in order to develop a synthetic dynamic framework for the study of a lifetime of relationships mediated by technology, we rely on four existing dynamic social theories for guidance about what elements to include in the model and what issues scholars might want to address.

Two of these dynamic theories address aging, and two of them address group development and change. These four theories share a focus on systematic and patterned changes over time. They vary on two dimensions: whether they examine these changes from a structural perspective or a developmental one and whether they focus on changes in the individual or changes in the family or friendship group. 
Individual development theory, as we will call the first type, focuses on systematic and patterned developmental changes in individuals. Here we draw on the work of Erikson (1959; Erikson, Erikson, \& Kivnick, 1989).

The second type of theory, which we call life course theory, examines systematic and patterned structural changes in the life course of individuals. Informed by sociological stratification scholarship, this approach was developed by Cain (1964), Clausen (1972), Ryder (1965), Riley, Johnson, and Foner (1972), and was more recently summarized by Bengtson and Allen (1993).

Family development theory is the third type. This approach features an interdisciplinary progression that integrates concepts and ideas from sociologists, demographers, economists, life course and human developmental theorists, and, more recently, family theorists. Scholars whose work is most prominent in the current application of family development theory include Glick (1947), Duvall (1957), Hill (1971), Rodgers (1977), Aldous (1978), Hill and Mattessich (1979), and, most recently, White (1991). Researchers who use this approach focus on the systematic and ordered sequence of developmental changes in families through attention to relationships within the group and on the construction of internal norms and roles (Aldous, 1978).

Network change theory, the fourth and final type, focuses on systematic and patterned structural changes in social networks (Suitor, Wellman, \& Morgan 1997). Although some network analysts study the interconnections among all of the individuals in a bounded population (e.g., an apartment building or a company), here we are interested in the literature examining "personal networks," or sets of ties developed and maintained by individuals that may extend beyond any identifiable boundaries.

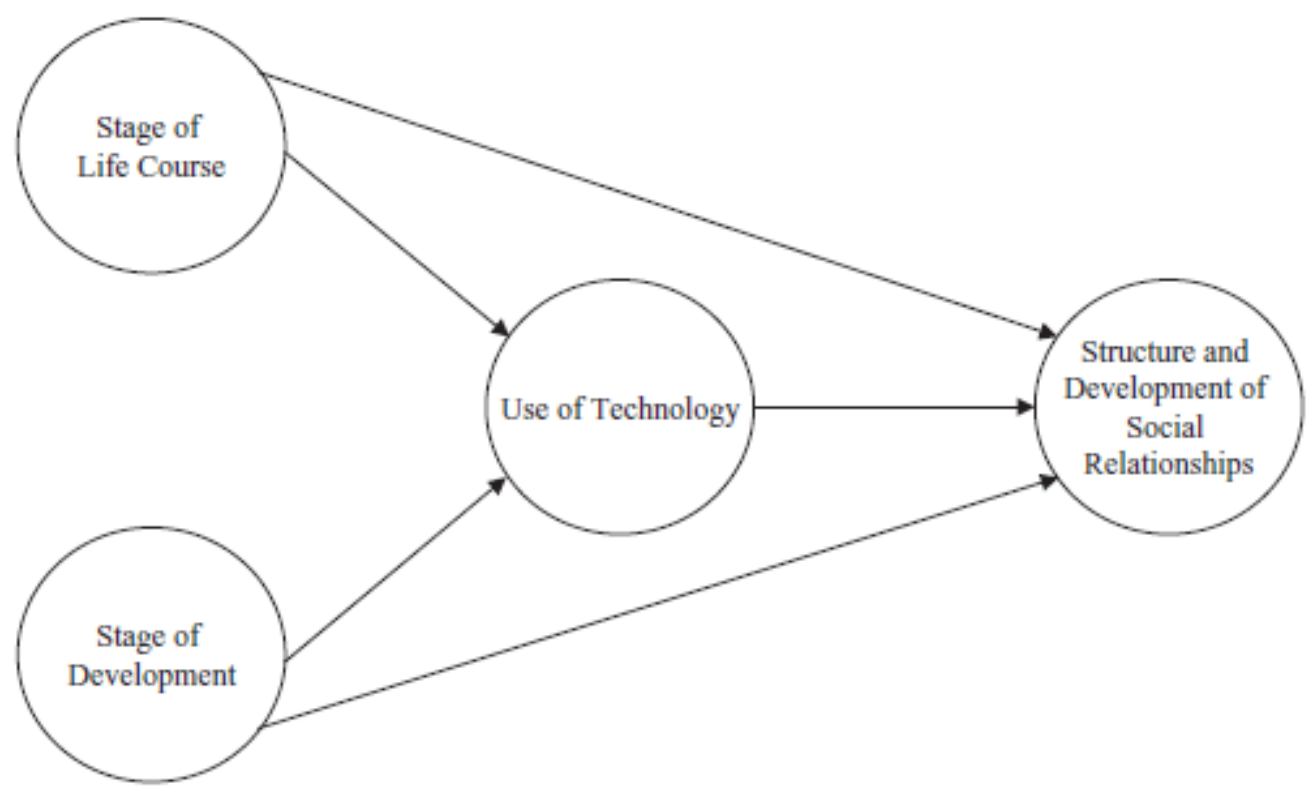

Figure 1. Synthetic Dynamic Model for the Study of a Lifetime of Relationships Mediated by Technology

See Figure 1 for the synthetic dynamic framework for the study of a lifetime of relationships mediated by technology integrating all four of these perspectives. This model can be used to 
guide studies designed to answer the questions: "How do changes in the life course and developmental stages of individuals affect their use of the technology?" and "How, in turn, does the use of this technology change the structure and development of social relationships?" Note that this framework also recognizes that stage of life course and stage of development have direct effects on the structure and development of social relationships, which researchers have studied extensively (see Blieszner \& Adams, 1992, for a review of relevant literature). Here we are more interested in the indirect effects than the direct ones. In this section, we therefore use individual development theory and life course theory to derive research questions regarding the effects of age on use of technology. Similarly, we use family development theory and network change theory to derive questions regarding the effects of the use of technology on the structure and development of social relationships. In each of the four following subsections, we elaborate on one of these theoretical approaches and discuss the research questions regarding the technological mediation of relationships that each of them raises.

\section{Individual Development Theory}

The basic premise of Erik Erikson's theory (1959) of individual psychosocial development is that increased social demands and responsibilities occur with physical maturation. As an individual acquires skills and abilities through physical development, she or he experiences growing pressure to change the way they interact with their environment. For example, as a child acquires language skills, she is expected to talk instead of cry for something she wants. These new social demands evoke a crisis the individual must overcome in order to advance toward healthy development.

Erikson (1959) proposed eight such crises during loosely defined ages and a psychosocial strength that is associated with the resolution of each crisis. The first crisis, trust versus mistrust, is experienced during infancy, and its resolution results in feelings of hope. Second, autonomy versus shame and doubt, is the stage associated with early childhood, leading to the development of will power. Third, initiative versus guilt occurs during what Erikson calls "play age" (i.e., around ages three or four years), leaving the child with a sense of purpose. Fourth, industry versus inferiority is the crisis school-age children face and is associated with the development of competence. Fifth, adolescents experience identity versus identity confusion, leading to fidelity in social relationships. Sixth, intimacy versus isolation occurs during young adulthood and is associated with the strength of love. Seventh, adults who successfully negotiate generativity versus stagnation develop their ability to care. Lastly, adults in old age face integrity versus despair and have the potential to find wisdom. Note that Erikson's later work (Erikson et al., 1989) described wisdom as the ability to maintain and learn to convey the integrity of experience, despite mental and physical decline. Each of these eight stages is influenced by and based on specific experiences at earlier ages. As a result, individuals continue to cope with an unresolved crisis throughout life while adding new issues with each stage.

Research Questions. How does this individually focused, developmental theory inform research on technology and relationships? Erikson's stages lend information about what issues are most important to individuals at a given stage of development. One example of a research question from this frame of reference is, "How does the stage of early childhood influence one' s use of technology to interact in a social environment?" Issues surrounding this question might include: 
1) how the degree of autonomy the child has developed facilitates or inhibits on-line communication and information exploration; 2) how the degree of shame and doubt a child feels has an impact on the use of technology to interact with and maintain the interest of adults; and 3) the degree to which the use of communication technology facilitates or inhibits the development of will power acted out in relationships.

A second example of a research question that follows from Erikson's stage theory is, "How does the emphasis on intimacy and isolation during early adulthood influence the use of technology as a social vehicle?" This line of research is currently most popular among researchers interested in the interplay between technology and relationships, as shown in the literature previously reviewed. Other issues that might be important here are: 1) types of communication technologies used by young adults who have successfully achieved intimacy (e.g., chat rooms, individual email contact, sex-based communication, technology as a supplement to face-to-face interaction, or technology as a way to initiate a relationship); 2) types of communication technologies used by young adults who have yet to resolve the intimacy-isolation crisis (e.g., on-line-only communication, chat rooms, sex-based communication); and 3) the circumstances under which young adults in intimate relationships use technology to maintain or further develop love.

\section{Life Course Theory}

Sociologists of age stratification developed life course theory, which focuses on the role of age in the social structure, and how, in turn, age affects the opportunities and constraints imposed on individuals. Building on the work of Cain (1964), Ryder (1965), and Clausen (1972), life course theorists view society as a succession of age cohorts of individuals who, as they age, are allocated to fill roles open to individuals of specific ages and are socialized regarding age-related expectations and sanctions (Riley et al., 1972). Successive cohorts are socialized differently and have different opportunities available to them because the characteristics of social contexts, including the age composition of society, change over time (Ryder, 1965). For this reason, behaviors, norms, and values are affected by the age of the individual, by the current period, and by the cohort of which the individual is a member.

Some life course researchers have focused their efforts on developing methods to specify the effects of age, period, and cohort and have developed cross-sequential longitudinal study designs for this purpose. Finding funding for such ambitious projects has proven difficult, so other life course researchers have developed less comprehensive study designs, focusing on how transitions from one stage of the life course to another affect the lives of individuals and the development of their friendship networks and families (e.g., Feld \& Carter, 1998; Lamme, Dykstra, \& Broese van Groenou, 1996; Leik \& Chalkley, 1997; Wellman, Wong, Tindall, \& Nazer, 1997).

Research Questions. The life course framework is useful for addressing questions related to understanding how technology mediates social relationships at different stages of the life course. The main question on this topic that can be derived from this theory is: How does the social context during which people are socialized, their biological age (i.e., physical and mental abilities), and their current social context affect their attitudes toward the use of technology and their use of technology to develop and maintain relationships? More specifically, what 
opportunities are offered for people at various stages of life to access technology and to use it to develop and maintain relationships? What relevant constraints are imposed on them? Do certain social roles provide occupants with more access to technology or more opportunities to learn how to use it to maintain and develop relationships than others? Are these social roles allocated based on age? Are people at some stages of life expected to use technology or to use it to maintain social relationships more than those at other stages of life? What are these expectations, what positive sanctions are given to those who meet them, and what negative sanctions are applied to those who fail to do so?

\section{Family Development Theory}

The basic premise of family development theory is that families continuously change and develop as prompted by the demands of family members (e.g., biological, psychological, and social needs), social expectations, and ecological constraints (Mattessich \& Hill, 1987). Each family member performs roles within the family over time, although the norms and specific behaviors in those roles are likely to be modified as family members mature and family interaction patterns evolve (Aldous, 1978). During this restructuring, families engage in developmental tasks, or activities that prepare them for the upcoming stage. The process of moving from one stage to another is dependent upon prior experiences (i.e., previous stages) and the length of time within the previous stage. Traditional stages include marriage without children, marriage with various aged children (e.g., infant, preschool, school age, adolescent, young adult), marriage with children who live outside the household, grandparenting, and marriage in late life. White (1991) has expanded these traditional stages to include divorce and remarriage, stages that were previously classified as nonnormative, or not widely accepted, but are now considered normative, or less deviant, family configurations. The classification of normative or nonnormative also refers to the timing of a particular stage. For example, the birth of the first child is expected to occur (normative) before the parents reach age forty and children are expected to leave (normative) their parents' home in their early to mid-twenties.

Family development theory allows scholars to organize family experiences into specific categories while recognizing the dynamic nature of stage progression. This classification identifies different issues and opportunities likely to face families at distinct points of development. White (1991) suggests that it is possible to investigate macro-level influences on the group level (i.e., family development), which provides a solid foundation for understanding the influence of technology on family relationships.

Research Questions. The primary research question offered by family development theory is, "How does technology influence family change over time?" More specifically, how does the use of on-line communication influence the norms and roles of family members? How is technology used in the developmental tasks that contribute to stage transitions? In what ways is the use of technology different across various stages of development and where is technology more influential? Does technology affect or contribute to the experience of off-time, or nonnormative stage transitions? How is the use of technology in early development qualitatively different from its use in later stages? A final question may be more relevant before communication technology further infiltrates families but may be impossible in the near future: How does family development occur in families equipped with technology allowing continuous availability and 
how does this process compare to families without access to these tools? Note that parallel questions could be posed about the development of friendship groups or networks.

\section{Social Network Change Theory}

The goal of social network analysis is the formal representation of the structure of personal relationships beyond the dyad (Feger, 1981). Over the past twenty-five years, social network researchers have focused their efforts on measuring and describing various characteristics of social networks (e.g., size, density, hierarchy, homogeneity, and solidarity, Adams \& Blieszner, 1994). Only recently have they begun to study changes in social networks over time and the processes underlying such changes (Suitor et al., 1997). It is thus a bit premature to use the phrase "social network change" as an adjective phrase modifying "theory." Nonetheless, we do so here because network researchers study changes in friendship networks as well as changes in social networks in general, including families. Furthermore, family developmental theorists emphasize internal process issues more than internal structural issues, and social network change theorists do the opposite (Blieszner \& Adams, 1992). Deriving research questions from both of these theories thus leads to a more comprehensive coverage of possible topics.

Research Questions. The main relevant question derived from the network change literature is: How does the use of technology change the structure of social networks (see Adams, 1998, for an earlier discussion of this topic)? Does on-line interaction affect the structure of face-to-face networks as well as the structure of virtual networks? More specifically, do people who spend time on-line have larger networks because more people with whom they share interests are easily available for interaction? Does time on-line detract from the time spent in face-to-face interaction and therefore lead to a deterioration in traditional relationships? Are on-line networks less dense because the people in them are less likely to know each other? Does on-line interaction increase the overall density of social networks because it is possible for people who would normally not cross paths do so easily and inexpensively in chat rooms and other virtual spaces? Are on-line networks less homogeneous than face-to-face networks because, in on-line contexts, structural barriers do not inhibit people occupying different social statuses from interacting with each other? If so, how does this affect the homogeneity of face-to-face networks? How are social hierarchies developed on-line? Is the process similar to the way that hierarchies develop in face-to-face groups? Are on-line networks lower in solidarity than face-toface networks? Finally, and of great demonstrated interest to journalists, does on-line interaction strengthen or weaken face-to-face relationships?

\section{Conclusions}

Since the development of the telegraph, communications technology has not been dependent on transportation technology. This means that communication is faster, more efficient, and more accessible than it was two hundred years ago. Although it is clear that these contextual changes have affected the way in which people develop and maintain relationships, theorists and researchers have been slow to adapt. With the "normalization" of Internet communication as part of everyday life (Wellman, Haase, Witte, \& Hampton, 2001), the need to study its effects has increased. Journalists have written a great deal about on-line relationships, but carefully designed, theoretically based research on the topic is rare. Furthermore, the sparse research 
literature does not address the effects of age on the use of technology or the potential interaction effect between age of participant, use of technology, and the development, structure, and process of family relationships and friendships. Most of the relevant research narrowly focuses on the use of on-line technology by one age group, particularly adults. The literature is thus not developed enough to inform policy or to suggest applications, but this has not stopped journalists from publishing articles including practical recommendations. These developments make it very important that scholars begin considering the implications of technological change for theory, conduct carefully conceived research on the mediating effect of technology on relationships of people of different ages, and disseminate confirmed results to the media and to appropriate agencies.

In this chapter, we have outlined a synthetic dynamic framework for the study of a lifetime of relationships mediated by technology. This framework integrates four dynamic social theories, individual development theory, life course theory, family development theory, and network change theory. We used individual development theory and life course theory to generate research questions regarding the effects of age on the use of technology. Similarly, we used family development theory and network change theory to derive questions regarding the impact of technology on the structure, process, and development of social relationships. Although we hope that this framework will inspire some well-designed research on the mediating effect of technology on relationships across the life span, even more do we hope that this chapter will inspire social relationship theorists from a variety of traditions to consider how current perspectives must be modified or expanded to adapt to recent changes in technology.

\section{References}

Adams, R. G. (1989). Conceptual and methodological issues in studying friendships of older adults. In R. G. Adams \& R. Blieszner (Eds.), Older adult friendship: Structure and process (pp. 17-41). Newbury Park, CA: Sage.

Adams, R. G. (1998). The demise of territorial determinism: Online friendships. In Placing friendship in context (pp. 153-182). Cambridge: Cambridge University Press.

Adams, R. G., \& Ammons, S. K. (2000, August). Face-to-face faculty discussions about teaching online. Paper presented at the annual meetings of the American Sociological Association, Washington, DC.

Adams, R. G., \& Blieszner, R. (1994). An integrative conceptual framework for friendship research. Journal of Social and Personal Relationships, 11, 163-184.

Aldous, J. (1978). Family careers: Developmental change in families. New York: Wiley.

Bengtson, V. L., \& Allen, K. R. (1993). The life course perspective applied to families over time. In P. G. Boss et al. (Eds.), Source book of family theories and methods (pp. 469-499). New York: Plenum. 
Blau, Z. S. (1961). Structural constraints on friendship in old age. American Sociological Review, 26, 429-439.

Blieszner, R., \& Adams, R. G. (1992). Adult friendship. Newbury Park: Sage.

Bryce, J. (2001). The technological transformation of leisure. Social Science Computer Review, 19(1), 7-16.

Cain, L. D., Jr. (1964). Life course and social structure. In R. E. L. Faris (Ed.), Handbook of modern sociology (pp. 272-309). Chicago: Rand McNally.

Carey, J. W. (1983). Technology and ideology: The case of the telegraph. Prospects, 8, 302-325.

Carlin, P. A., \& Surk, B. (2000). Cyber survivor. People Weekly, 53 (21), 95-96.

Castells, M. (1996). The rise of the network society. Cambridge, UK: Blackwell.

Clausen, J. A. (1972). The life course of individuals. In M.W. Riley, M. E. Johnson, \& A. Foner (Eds.), Aging and society: A sociology of age stratification (Vol. 3, pp. 457-514). New York: Russell Sage.

Cooley, C. H. (1983 [1909]). Social organization: A study of the larger mind. New York: Charles Scribner's Sons.

Craven, P., \& Wellman, B. (1974). The network city. In M. P. Effrat (Ed.), The community: Approaches and applications. Glencoe, IL: The Free Press.

Cuba, L. (1991). Models of migration decision making reexamined: The destination search of older migrants to Cape Cod. The Gerontologist, 31, 204-209.

Cuba, L. (1992). Families and retirement in the context of elderly migration. In M. Szinovacz, D. J. Ekerdt, \& B. H. Vinick (Eds.), Families and retirement (pp. 205-211). Newbury Park, CA: Sage.

Cuba, L., \& Hummon, D. M. (1993). Constructing a sense of home: Place affiliation and migration across the life cycle. Sociological Forum, 8, 547-572.

Duvall, E. M. (1957). Family development (1st ed.). Philadelphia: Lippincott.

Duxbury, L. E., Higgins, C. A., \& Thomas, D. R. (1996). Work and family environments and the adoption of computer-supported supplemental work-at-home. Journal of Vocational Behavior, $49(1), 1-23$.

Effrat, M. P. (1974). Approaches to community: Conflicts and complementarities. In M. P. Effrat (Ed.), The community: Approaches and applications. Glencoe, IL: The Free Press. 
Encyclopedia Britannica, Inc. (1997). Formation of airlines. [Computer software].

Encyclopedia Britannica, Inc. (1997). History of technology. [Computer software].

Encyclopedia Britannica, Inc. (1997). Pony Express. [Computer software].

Encyclopedia Britannica, Inc. (1997). Postal system. [Computer software].

Erikson, E. H. (1959). Identity and the life cycle. New York: Norton.

Erikson, E. H., Erikson, J. M., \& Kivnick, H. Q. (1989). Vital involvement in old age. New York: Norton.

Feger, H. (1981). Analysis of social networks. In S. Duck \& R. Gilmour (Eds.), Personal relationships (Vol. 1, pp. 91-108). London: Academic Press.

Feld, S., \& Carter,W. C. (1998). Foci of activity as changing contexts for friendship. In Placing friendship in context (pp. 136-152). Cambridge: Cambridge University Press.

Fischer, C. S., \& Carroll, G. R. (1988). Telephone and automobile diffusion in the United States, 1902-1937. American Journal of Sociology, 93(5), 1153-1178.

Flaherty, L. M., Pearce, K. J., \& Rubin, R. B. (1998). Internet and face-to-face communication: Not functional alternatives. Communication Quarterly, 46, 250-269.

Galston, W. A. (2000). Does the Internet strengthen community? National Civic Review, 89(3), 193.

Gans, H. (1962). The urban villagers. Glencoe, IL: The Free Press.

Gans, H. (1967). The Levittowners. New York: Pantheon.

Gibson, J. (2001). Don’ t forget kids' privacy. Library Journal, 126 (1), 7.

Glick, P. C. (1947). The family cycle. American Sociological Review, 12, 164-174.

Goldsborough, R. (1998, Jan.-Feb.). The curious phenomenon of online romance. Link-Up, 15(1), 15.

Harmon, A. (1998, August 30). Sad, lonely world discovered in cyberspace. The New York Times, p. 1.

Hays, R. B. (1984). The development and maintenance of friendship. Journal of Social and Personal Relationships, 1, 75-98. 
Hays, R. B. (1985). A longitudinal study of friendship development. Journal of Personality and Social Psychology, 48, 909-24.

Hill, R. (1971).Modern systems theory and the family: A confrontation. Social Science Information, 10, 7-26.

Hill, R., \& Mattessich, P. (1979). Family development theory and life span development. In P. Baltes \& O. Brim (Eds.), Life span development and behavior (Vol. 3). New York: Academic Press.

Hokanson, D. (1988). The Lincoln Highway: Main Street across America. Iowa City, IA: University of Iowa Press.

Homans, G. C. (1950). Social behavior: Its elementary forms. New York: Harcourt, Brace, and Jovanovich, Inc.

Iliff, H. A. (2002). Middle school Internet usage: Is there a gender difference? Paper presented at the annual meetings of the Southern Sociological Society, Baltimore, MD, April.

Jennings, S. R. (2001). Older adults and computers: A study of Wellspring Retirement Community residents. Report on internship submitted as partial fulfillment of requirements for the Master's of Arts degree in Sociology, Department of Sociology, University of North Carolina at Greensboro, Greensboro, NC, December 4.

Klein, M. (1993). What hath God wrought? American Heritage of Invention and Technology, $8(4), 34-43$.

Kraut, R., Patterson, M., Lundmark, V., Kiesler, S., Mukopadhyay, T., \& Scherlis, W. (1998). Internet paradox: A social technology that reduces social involvement and psychological wellbeing? American Psychologist, 53, 1017-1031.

Lamme, S., Dykstra, P. A., Broese van Groenou, M.I. (1996). Rebuilding the network: New relationships in widowhood. Personal Relationships, 3(4), 337-349.

Leik, R. K., \& Chalkley, M. A. (1997). On the stability of network relations under stress. Social Networks, 19, 63-74.

Liebow, E. (1967). Tally's corner. Boston: Little, Brown.

Litwak, E., \& Szelenyi, I. (1969). Primary group structure and their functions: Kin, neighbors, and friends. American Sociological Review, 34(4), 465-481.

Martin, M. (1991). Communication and social forms: The development of the telephone, 18761920. Anitpode, 23(3), 307-333. 
Mattessich, P., \& Hill, R. (1987). Life cycle and family development. In M. B. Sussman \& S. K. Steinmetz (Eds.), Handbook of marriage and the family (pp. 437-469). New York: Plenum.

Milewski, K., Hatala, M. N., \& Baack, D. W. (1999). Downloading love: A content analysis of Internet personal advertisements placed by college students. College Student Journal, 33(1), 124.

Mills, R. (1998). Cyber: Sexual chat on the Internet. Journal of Popular Culture, 32(3), 31-46.

O’Donnell, J. J. (1998, February 13). Tools for teaching: Personal encounters in cyberspace. The Chronicle of Higher Education.

O’Toole, K. (2000, May). How the Internet is changing daily life. Direct Marketing, 63(1), 50.

Paccagnella, L. (1997). Getting the seats of your pants dirty: Strategies for ethnographic research on virtual communities. Journal of Computer Mediated Communication, 3(1), http://jcmc.huji.ac.il/vol3/issue1/.

Parks, M. R., \& Floyd, K. (1996). Making friends in cyberspace. Journal of Communication, 46, 80-97.

Parks, M. R., \& Roberts, L. D. (1998). "Making MOOsic": The development of personal relationships on-line and a comparison to their off-line counterparts. Journal of Social and Personal Relationships, 15, 517-537.

Parsons, T. (1949). The social structure of the family. In R. N. Anshen (Ed.), The family: Its function and destiny. New York: Harper and Row.

Perry, J. (2000, February 28). Only the cyberlonely. U. S. News \& World Report, 128 (8), 62.

Pihlblad, C. T., \& McNamara, R. L. (1965). Social adjustment of elderly people in three small towns. In A. Rose \&W. A. Peterson (Eds.), Older people and their social world. Philadelphia: F. A. Davis.

Pool, I. de S. (1983). Forecasting the telephone: A retrospective technology assessment. Norwood, NJ: Ablex.

Reynolds, G. F. (1977-79). Early wireless and radio in Manitoba, 1909-1924. Transactions of the Historical and Scientific Society of Manitoba, 34-35, 89-113.

Rheingold, H. (1991). Virtual reality. New York: Summit Books.

Rierdan, J. (1999). Internet-depression link? American Psychologist, 54, 781-782.

Riley, M. W., Johnson, M., \& Foner, A. (1972). Aging and society: A sociology of age stratification (Vol. 3). New York: Russell Sage. 
Rodgers, R. H. (1977). The family life cycle concept: Past, present, and future. In J. Cuisenier (Ed.), The family life cycle in European societies. Berlin: Mouton de Gruyter.

Rohlfing, M. E. (1995). “Doesn't anybody stay in one place anymore?” An exploration of an understudied phenomenon of long-distance relationships. In J. T. Wood \& S. Duck (Eds.), Understudied relationships: Off the beaten track. Newbury Park, CA: Sage.

Rose, A. M. (1965). Aging and social interaction among the lower classes of Rome. Journal of Gerontology, 20, 250-253.

Rosenmayr, L. (1977). The family: A source of hope for the elderly? In E. Shanas \& M. B. Sussman (Eds.), Family, bureaucracy, and the elderly (pp. 132-157). Durham, NC: Duke University Press.

Ryder, N. B. (1965). The cohort as a concept in the study of social change. American Sociological Review, 30, 843-861.

Scharlott, B.W.,\&Christ,W. G. (1995). Overcoming relationship-initiation barriers: The impact of a computer-dating system on sex role, shyness, and appearance inhibitions. Computers in Human Behavior, 11, 191-204.

Shapiro, J. S. (1999). Loneliness: Paradox or artifact? Response to Kraut et al., 1998. American Psychologist, 53,1017.

Short, J., Williams, E., and Christie, B. (1976). The social psychology of telecommunications. New York: John Wiley and Sons.

Siegal, J., Dubrovsky, V., Kiesler, S., \& McGuire, T. (1986). Group processes in computermediated communication. Organizational Behavior and Human Decision Processes, 37, 157-87.

Smith, M. A., \& Kolluck, P. (1999). Communities in cyberspace. London, Boston: Routledge.

Soderbergh, S. (Producer), \& Ross, G. (Director). (1998). Pleasantville. Film. (available from Warner Home Video). Theatrical release: October 23.

Suitor, J. J., Wellman, B., \& Morgan, D. L. (1997). It's about time: How, why and when networks change. Social Networks, 19, 1-7.

Tiene, D. (2000). Online discussions: A survey of advantages and disadvantages compared to face-to-face discussions. Journal of Educational Multimedia and Hypermedia, 9, 371.

Tolson, J. (2000, May 15). A not-so-lonely crowd: Wired loners business-personality. U.S. News \& World Report, 128(19), 46.

UCLA Center for Communication Policy (2001). Surveying the digital future. The UCLA Internet Report 2001. Los Angeles: UCLA Center for Communication Policy. 
U.S. Census Bureau (1997). Computer use in the United States. Current Population Reports P20522.

Warthman, F. (1974). Telecommunication and the city. Annals of the American Academy of Political and Social Sciences, 412, 127-137.

Waskul, D., Douglass, M., \& Edgley, C. (2000). Cybersex: Outercourse and the enselfment of the body. Symbolic Interaction, 23(4), 375-397.

Watt, D., \& White, J.M.(1999). Computers and the family life: A family development perspective. Journal of Comparative Family Studies, 30, 1-15.

Webber,M.M. (1973). Urbanization and communications. In G. Gerbner, L. P. Gross, \& W. H. Melody (Eds.), Communications, technology, and social policy. New York: John Wiley \& Sons.

Wellman, B., Haase, A. Q., Witte, J., \& Hampton, K. (2001). Does the Internet increase, decrease, or supplement social capital? American Behavioral Scientist, 45(3), 436-455.

Wellman, B., Wong, R. Y., Tindall, D., \& Nazer, N. (1997). A decade of network change: Turnover, persistence and stability in personal communities. Social Networks, 19, 27-50.

White, J. M. (1991). Dynamics of family development: The theory of family development. New York: Guilford.

Whyte, W. F. (1943). Street corner society. Chicago: University of Chicago Press.

Whyte, W. H. (1956). The organization man. New York: Doubleday.

Zillmann, D., \& Jennings, B. (1988). Effects of prolonged consumption of pornography on family values. Journal of Family Issues, 9, 518-544. 